\title{
MRS 2000: A Vision of Service to the Materials Community
}

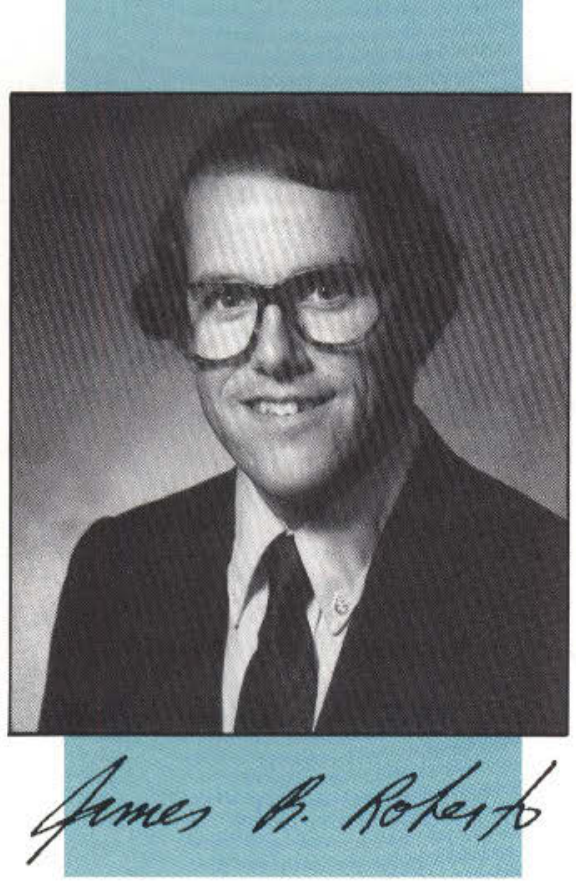

The Materials Research Society has achieved phenomenal success in the past decade building on the fundamental importance of multidisciplinarity in materials research. Remarkably, growth has been sustained on multiple fronts: membership, technical meetings, publications, and educational and public affairs activities. However, without a collective vision of the desired future and a set of challenging goals to implement that vision, continued success of the Society cannot be assured. So, where does MRS want to be in the year 2000 ?

\section{Empowered volunteerism is the engine of MRS.}

A group of MRS "proactivists," led by John Baglin and the Long Range Planning Committee, has been debating this question for the past 18 months. An image has emerged of an MRS in the next century which is as new and vital as the MRS of today. MRS seeks leadership in interdisciplinary technical programming and innovative meeting formats, affiliations with other materials-related societies, interactions with the worldwide materials community, publications content and technology, materials education, public affairs related to materials research, and empowered volunteerism.

Empowered volunteerism is the engine of MRS. We empower our meeting chairs to create a new technical meeting essentially from scratch every six months. They in turn empower symposium organizers to define the state of the art in their symposia. We empower our committees to develop policy which forms the basis of Executive Committee and headquarters actions. With empowerment comes responsibility, "ownership of the problem," personal commitment, and success. One of the great pleasures of serving as MRS president is the opportunity to observe the MRS volunteer engine at work. This engine is both key to our future as a dynamic technical society and a profound influence on the future of materials research.

The vision brought forth by the MRS 2000 committee is already being created by the MRS of today. Consider, for example, experiments with satellite Symposium $X$ broadcasts, formation of the International Union of Materials Research Societies (see February 1991 MRS Bulletin, p. 33), and organization of the Washington Materials Forum in cooperation with eight leading materials-related societies (see April 1991 MRS Bulletin, p. 23). We have a long way to go, but the course is true and steady. The challenges and opportunities are immense.

In meetings and publications, we will see new technology and venues over the next decade. Significant advances will occur in electronic publishing and teleconferencing. MRS must understand the implications of these advances and provide leadership in their productive use.

Relationships with parity organizations both abroad and at home will become increasingly important with the internationalization of the economy and the critical role played by materials research in U.S. economic competitiveness. On the home front, the ability of the diverse materials community to establish and communicate responsible priorities to policymakers is vital. As an interdisciplinary society, MRS is in a unique position to contribute to this essential unity in the materials community.

In public affairs, the influence of MRS is rapidly growing. In February, our Washington Office under the leadership of Elton N. Kaufmann organized and sponsored a multisociety reception featuring a presentation by U.S. Representative George Brown, chairman of the House Science and Technology Committee. In July, MRS hosted a meeting of the Congressional Advanced Materials Caucus (See From Washington article in this issue.) Former MRS councillor Bill Appleton spoke on the recent National Research Committee (NRC) report, A National Agenda for Materials Science and Engineering, which was published by MRS for the NRC. MRS has been asked for and has provided technical comment on several pieces of advanced materials legislation currently pending in Congress. The MRS role in public affairs will continue to emphasize communication between policymakers and the materials community and nonpolitical, technical support for the government in the materials field.

In education, MRS created a grassroots task force in April, chaired by Ken Eckelmeyer, to help bolster primary and secondary school science education in the U.S. Grades three through eight have been identified as the critical years in which the largest numbers of students lose interest in science and math. An outgrowth of education initiatives in several MRS committees, this task force has established a goal of fielding a dedicated cadre of MRS scientists and engineers in effective cooperative programs with the schools to improve science and math education. This volunteer program will be coordinated with other national education initiatives such as the newly formed Engineers for Education, a network of professional societies with a total membership exceeding one million.

MRS 2000 will be larger and broader than the MRS of today, with more activities and more visibility on the national scene. But MRS will also be very much the same, fulfilling a vision of service to the materials community through the collective efforts of hundreds of volunteers. MRS volunteers are making a difference in the materials community.

Jim Roberto 